\title{
A Robust Regulator Designed for Chinese House Market to Deal with Speculation
}

\author{
Tongxin \\ Economics \&Management Department \\ Shenzhen Graduate school of Harbin University of \\ Technology \\ Shenzhen, China \\ e-mail: sasasam@163.com
}

\author{
Wang Susheng \\ Economics \&Management Department \\ Shenzhen Graduate school of Harbin University of \\ Technology \\ Shenzhen, China \\ e-mail: 110928125@qq.com
}

\begin{abstract}
To deal with the speculation in Chinese house market which leads to the sustained and rapid rising of house price and the accumulation of bubbles, and leads to the inefficiency of resource allocation, this paper designed a robust regulator for Chinese house market through the discussion of the reason of excepted house price that aroused speculation based on the cybernetics, the robustness regulator is an innovated land biding method: the one who return the highest proportion of houses built on this land would get it, and the government lease the houses which was drafted at random at the price of market clearing. The robust regulator made the Chinese housing market remained robustness under the circumstances with speculation. The design of this robust regulator had some theoretical contribution to Chinese market economy.
\end{abstract}

Keywords- House Market; Robust Regulator; Dynamics; Stability; Innovated land biding method; Price mechanism

\section{INTRODUCTION}

The house price of China has been in a state of sustained rising for a long time (Chow, 2010). The opinions about the sustained and rapid rising were divided into two kinds, the one kind thought the sustained and rapid rising was aroused by speculate demand, and speculate demand will arouse more rapidly rising (Kuang Weida, 2010); another kind thought the sustained and rapid rising of house price could be interpreted by incomes, and there are no bubbles in Chinese housing market, the invention on house price in any format will not get the aim (Chow, 2010). Some ones with first opinion suggested some administrative invention to restrain the housing speculation, such as to decrease the financial sustain or to place restriction on the speculation buying. Some ones with second opinion follow the principle of market, took the price as the token of scarcity, thought the invention in any kinds will decrease the efficiency of resource allocation, suggest deregulating the restrain about cultivated land to build house on it.

Market mechanism, which was called as price mechanism, was a robust regulator in cybernetics concept, the robustness analysis for dynamical system must be adapted for Chinese house market and can find the reason of price diverge, and the design of robustness regulator must be suit for solving the dilemma of Chinese house market.

\section{THE ROBUST REGULATOR CHARACTER OF PRICE MECHANISM}

\section{A. The concept of robust regulator}

Robust and Robustness were concepts of modern cybernetics. A cybernetics system is system that makes the controlled object run in the expected route, most of the cybernetics systems are designed based on the principle of feedback. Robustness means the stability, gradually regulative and, dynamic characteristics will not change when the uncertainty happened in some range, and it means the feedback system is robust to bear the impact of the uncertainty. To a controlled system, it needs a controlled variable to deal with the disturbance or impact.

\section{B. The regulator character of price mechanism}

There is one good in market, the demand and supply are function of price of this good, that means:

$$
\left\{\begin{array}{l}
S=S(p) \\
D=D(p)
\end{array}\right.
$$

The target of control, $E(p)$, is the equilibrium of demand and supply, and the controlled variable is the price, $p_{\text {,so: }}$

$$
E(p)=D(p)-S(p)=0
$$

Follow the theory of robust regulator, the regulator $\xi$, must be abided by:

$$
\frac{d \xi(t)}{d t}=D(p)-S(p)
$$

The controlled variable $p$, is the feedback of states of system and regulator, it must be designed as follow:

$$
p(t)=k \cdot \xi(t)
$$

Where:

$k>0$, is the velocity of adjustment.

Derivative the equation (4) with respect to time ${ }^{t}$, get:

$$
\frac{d p(t)}{d t}=k \frac{d \xi(t)}{d t}
$$

Take the equation (3) into equation (5):

$$
\frac{d p(t)}{d t}=k(D(p)-S(p))
$$


Equation (6) was a price making tactics designed followed the theory of robustness regulator, and it just be a market price making tactics without any design. (Zhang Jinshui, 2000).

\section{The robustness of price mechanism}

Market mechanism or price mechanism, is described as a differential function as follow:

Where:

$$
\dot{p}=\frac{d p(t)}{d t}
$$

, the derivative of price with respect to time; $k>0$, the velocity of adjustment.

Equation (7) is the same as equation (6).

$D(p)-S(p)>0$, the price ascend, $\dot{p}>0$; on the

$D(p)-S(p)<0$, the price descend, $\dot{p}<0$.

To study the stability of $\dot{p}=k(D(p)-S(p))$, gave a function:

$$
V(D(p)-S(p))=\frac{1}{2} k(D(p)-S(p))^{2}
$$

where: $k>0$, it is a constant.

The function satisfied:

$$
\text { (1) } V(p) \geq 0 \text {; }
$$

And get equal only when $D(\bar{p})=S(\bar{p})$, it means there is a $\bar{p}$ makes:

This function was named as Lyapunov function, if Lyapunov function satisfied:

$$
\text { (3) } \dot{V}<0 \text {; }
$$

Then the function is gradually steady function (Zhang Jinyan, 2000).

$$
\text { Where: } \dot{V}=\frac{d V}{d t} \text {, it is the derivative of Lyapunov }
$$
function with respect to time.

$$
\dot{V}=\frac{d V}{d t}=k(D(p)-S(p))\left(\frac{d(D(p)-S(p))}{d p} \cdot \frac{d p}{d t}\right)
$$

Get:

$$
\dot{V}=\frac{d V}{d t}=k^{2}(D(p)-S(p))^{2}\left(\frac{d D(p)}{d p}-\frac{d S(p)}{d p}\right)
$$

$$
\dot{p}=k(D(p)-S(p))
$$
opposite, when

$$
\text { (2) } V(\bar{p})=0 \text {; }
$$

\section{THE AFFECTION OF SPECULATION TO THE ROBUSTNESS OF PRICE MECHANISM}

A. The main reason arouse housing speculation is the expectation price of house

There are apparent speculations in Chinese housing market, reluctant to sell, land hoarding, and houses vacating are in the same aim of speculation. Houses are necessaries, because of the rental of house, houses are asset too. When the price of asset rising sustained and rapid, it must leads to speculation, the price rising at first arouse the expectation of price rising and arouse more speculators, then the more price rising (Kindleberger, 1978). When the expectation of rising is turn, it will lead price drop suddenly, and will end with finance crisis. It is the reason for this paper to find a method to deal with the speculation on Chinese real estate.

\section{B. The key factor of excepted price of house is land price}

Under the condition of "the conduction cost gauged by the index of construction material price has no raised from 1986", "the cost of land buying as the main cost of construction cost has raised at the rate of $11.8 \%$ every year from 1997 to 2007", "if take the ratio of land buying cost to the housing price as the ratio of land cost to total construction cost, the ratio has raised from 19\% in 1997 to $31 \%$ in 2006",(Chow,2010), the land buying cost which is the most major component of construction cost is the key factor of the excepted price of house.

we have:

$$
p_{t+1}^{e h}=f\left(p_{t}^{l}\right)
$$

Where: $p_{t+1}^{e h}$, the excepted house price of term $t+1$;

$$
p_{t}^{l} \text {, the land price of term }{ }^{t} \text {. }
$$

Subscript means term, superscript $h$ means house, $l$ means land, ${ }^{e}$ means exception;

$$
f \text {, function, and } f^{\prime}>0 \text {, the house exception price }
$$
of next term is an increase function of the land price of this term, so: :

$$
\frac{d p_{t+1}^{e h}}{d p_{t}^{l}}>0
$$

Take the expected price of house into account, the demand function of housing is:

$$
D_{t}^{h}(\bullet)=D_{t}^{h}\left(p_{t}^{h}, p_{t+1}^{e h}\right)
$$

To deal with speculation on house, we divided the housing demand into three kinds, residential demand, investment demand, and speculation demand:

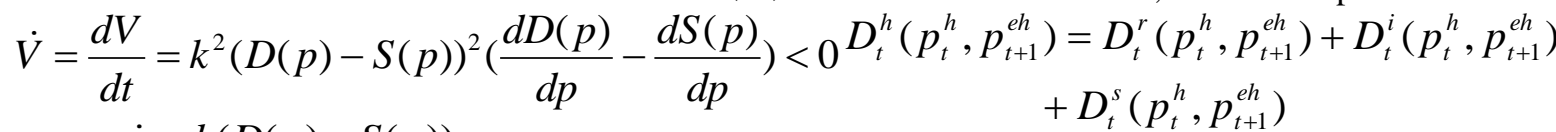

System $\dot{p}=k(D(p)-S(p))$ is gradually steady. mechanism.
Where:

$$
\begin{aligned}
& D_{t}^{r}\left(p_{t}^{h}, p_{t+1}^{e h}\right), \text { demand for resident; } \\
& D_{t}^{i}\left(p_{t}^{h}, p_{t+1}^{e h}\right), \text { demand for investment; }
\end{aligned}
$$


$D_{t}^{s}\left(p_{t}^{h}, p_{t+1}^{e h}\right)$, demand for speculation.

The expected price of house has positive affection to three kinds of demand:

$$
\frac{\partial D_{t}^{h}(\bullet)}{\partial p_{t+1}^{e h}}>0
$$

It means when the expectation price of house is rise, the three kinds of demand of house is increase.

The supply function of house:

$$
S_{t}^{h}(\bullet)=S_{t}^{h}\left(p_{t}^{h}, p_{t+1}^{e h}\right)
$$

And:

$$
\frac{\partial S_{t}^{h}(\bullet)}{\partial p_{t+1}^{e h}}<0
$$

It means when the expectation price of house is rise, the supply of house is decrease.

\section{The exception price of housing price effect the land price}

Under the land biding method, the land price in this term was decided by the expected price of house price in next term, the expected price of next term comes from the price before, and the most important is the house price of this term. It means:

$$
\begin{aligned}
& p_{t}^{l}=g\left(p_{t+1}^{e h}\right) \\
& p_{t+1}^{e h}=j\left(p_{t}^{h}\right)
\end{aligned}
$$

Where: $p_{t}^{l}$, the land price of term $t ; p_{t+1}^{e h}$, the expected housing price of next term $t+1$; Subscript means term, superscript $h$ means house, $l$ means land, $e$ means expectation; $g$, function, and $g^{\prime}>0$, the land price of this term is an increase function of the excepted price of house in next term; $j$, function, and $j^{\prime}>0$, the excepted price of house in next term is an increase function of land price in this term.

Put (19) into (18), we get:

$$
\begin{aligned}
& p_{t}^{l}=g\left(j\left(p_{t}^{h}\right)\right) \\
& \quad \frac{d p_{t}^{l}}{d p_{t}^{h}}=g^{\prime} \cdot j^{\prime}>0 \\
& \text { and, , so we have: }
\end{aligned}
$$

$$
\frac{d p_{t}^{l}}{d p_{t}^{h}}>0
$$

It states the land price of this term is an increase function of the house price in this term.

\section{The exception price of housing price effect the land price}

The demand and supply of house will make expectation on the house price of next term through the land price of this term, and change the demand and supply under the drive of speculation, speculate demand becomes the main part in house demand (Li Zunbai, 2010).

To the whole Chinese housing market, the supply and demand looks as continuous function, when $\Delta t \rightarrow 0$, the continuous function of housing market price mechanism with speculation is:

$$
\frac{d p^{h}}{d t}=k\left(D^{h}\left(p^{h}, p^{e h}\right)-S^{h}\left(p^{h}, p^{e h}\right)\right)
$$

The Lyapunov function of housing market price mechanism with speculation is:

$$
V(D(\bullet)-S(\bullet))=\frac{1}{2} k\left(D^{h}\left(p^{h}, p^{e h}\right)-S^{h}\left(p^{h}, p^{e h}\right)\right)^{2}
$$

The Lyapunov function descript by equation (22) is a function of demand and supply, and a function of price change in equation ( $6^{\prime}$ ), because of the exist of speculation, the demand and supply of house is not only the function of self price of house, but also the function of expected price of house.

Derivative the Lyapunov function (21) with respect to time, for brief, $D^{h}\left(p^{h}, p^{e h}\right)$ shorthand as $D^{h}(\bullet)$, $\left.S^{h}\left(p^{h}, p^{e h}\right)\right)$ shorthand as $S^{h}(\bullet)$, we get:

$$
\begin{aligned}
\dot{V}= & k \cdot\left(D^{h}(\bullet)-S^{h}(\bullet)\right)\left(\frac{\partial\left(D^{h}(\bullet)-S^{h}(\bullet)\right)}{\partial p^{h}}\right. \\
& \left.+\frac{\partial\left(D^{h}(\bullet)-S^{h}(\bullet)\right)}{\partial p^{e h}} \cdot \frac{d p^{e h}}{d p^{l}} \cdot \frac{d p^{l}}{d p^{h}}\right) \cdot \frac{d p^{h}}{d t}
\end{aligned}
$$

$$
\begin{aligned}
& \text { Put }\left({ }^{\prime}{ }^{\prime}\right) \text { into (23), we get: } \\
& \begin{aligned}
\dot{V}= & k^{2} \cdot\left(D^{h}(\bullet)-S^{h}(\bullet)\right)^{2}\left(\left(\frac{\partial D^{h}(\bullet)}{\partial p^{h}}-\frac{\partial S^{h}(\bullet)}{\partial p^{h}}\right)\right. \\
& \left.+\left(\frac{\partial D^{h}(\bullet)}{\partial p^{e h}}-\frac{\partial S^{h}(\bullet)}{\partial p^{e h}}\right) \cdot \frac{d p^{e h}}{d p^{l}} \cdot \frac{d p^{l}}{d p^{h}}\right)
\end{aligned}
\end{aligned}
$$

(24)

$$
\begin{aligned}
& \text { In equation (24), } \\
& k^{2}>0 \text {; } \\
& \left(D^{h}(\bullet)-S^{h}(\bullet)\right)^{2}>0 ; \\
& \left(\frac{\partial D^{h}(\bullet)}{\partial p^{h}}-\frac{\partial S^{h}(\bullet)}{\partial p^{h}}\right)<0
\end{aligned}
$$

From (12), (15), (17), and (21), we get:

$$
\begin{aligned}
& \left(\frac{\partial D^{h}(\bullet)}{\partial p^{e h}}-\frac{\partial S^{h}(\bullet)}{\partial p^{e h}}\right) \cdot \frac{d p^{e h}}{d p^{l}} \cdot \frac{d p^{l}}{d p^{h}}= \\
& \left(\frac{\partial D^{r}}{\partial p^{e h}}+\frac{\partial D^{i}}{\partial p^{e p}}+\frac{\partial D^{s}}{\partial p^{e p}}-\frac{\partial S^{h}}{\partial p^{e h}}\right)>0
\end{aligned}
$$

So, the signal of (24) is uncertainty, the signal of (24) is decided by the difference between the sensitivity of house demand and supply to house price and the sensitivity of house demand and supply to expected house price. Under the condition that the main part of demand is speculation demand, the sensitivity of house demand and 
supply to house price is smaller than the sensitivity of house demand and supply to expected house price. We have:

$$
\begin{aligned}
\dot{V}=k^{2} \cdot\left(D^{h}(\bullet)-S^{h}(\bullet)\right)^{2} & \left(\left(\frac{\partial D^{h}(\bullet)}{\partial p^{h}}-\frac{\partial S^{h}(\bullet)}{\partial p^{h}}\right)\right. \\
& \left.+\left(\frac{\partial D^{h}(\bullet)}{\partial p^{e h}}-\frac{\partial S^{h}(\bullet)}{\partial p^{e h}}\right) \cdot \frac{d p^{e h}}{d p^{l}} \cdot \frac{d p^{l}}{d p^{h}}\right)>0
\end{aligned}
$$

So, Chinese house market is not robust system, the system has not stability, it states that the house price is diverge.

\section{THE DESIGN OF ROBUST REGULATOR FOR HOUSING MARKET}

\section{A. A. The innovated method of land biding}

In the course of house product, under the condition of non-changed technique, the marginal production of land will not change. The increase of land price means the land owner gets the more share of production, so we design an innovated land biding method:

Change the one who pay the most money to government gets the land to develop into the one who return the highest proportion of house to government gets the land to develop, and the government lease the houses drafted in random at the price of market clear.

\section{B. The Lyapunov function of housing market under the innovated method of land biding}

Under the condition that the one who will return the highest proportion of house to government will get the land to develop, "land price" increase means the more proportion of house will return to government, and government will lease the house that was returned by developer at price of market clear, it means the higher "land price" is, the lower rental is. All three kinds of demand of house $D^{r}(\bullet), D^{i}(\bullet), D^{s}(\bullet)$, and the supply of house $S(\bullet)$ will change.

The purpose of $D^{r}(\bullet)$ is to resident, under the innovated land biding method, the factors that effect $D^{r}(\bullet)$ included the price of house and the expected rental of house, $D^{r}(\bullet)=D^{r}\left(p^{h}, p^{e R}\right)$, here $p^{e R}$ is the expected rental of house, and:

$$
\frac{\partial D^{r}}{\partial p^{h}}<0
$$

The resident demand will decrease when the house price is increase;

$$
\frac{\partial D^{r}}{\partial p^{e R}}>0
$$

The resident demand will decrease when the expected rental decrease.
The purpose of $D^{i}(\bullet)$ is to lease, under the innovated land biding method, the factors that effect $D^{i}(\bullet)$ included the price of house and the expected rental of house, $D^{i}(\bullet)=D^{i}\left(p^{h}, p^{e R}\right)$, here $p^{e R}$ is the expected rental of house, the principle of investment decision is maximum the difference of present price of rental (the present value of dividend) and the cost of house (asset price), we have:

$$
\frac{\partial D^{i}}{\partial p^{h}}<0
$$

The investment demand will decrease when the house price is increase;

$$
\frac{\partial D^{i}}{\partial p^{e R}}>0
$$

The investment demand will decrease when the expected rental is decrease.

The purpose of $D^{s}(\bullet)$ is to sell, the factors that effect $D^{s}(\bullet)$ included the expected price of house and the sum of resident demand and investment demand, $D^{s}(\bullet)=D^{s}\left(\left(D^{r}(\bullet)+D^{i}(\bullet)\right), p^{e h}\right)$, and:

$$
\begin{aligned}
& \frac{\partial D^{s}}{\partial\left(D^{r}+D^{i}\right)}>0 \\
& \frac{\partial D^{s}}{\partial p^{e p}}>0
\end{aligned}
$$

$S^{h}(\bullet)$ means the houses used for sell, under the innovated land biding method, the total amount of house supply was decided by the amount of land supply and "land price" was affected by the expected price of house and the expected rental, $S^{h}(\bullet)=S^{h}\left(p^{e h}, p^{e R}\right)$ :

$$
\begin{aligned}
& \frac{\partial S_{t}^{h}}{\partial p^{e h}}<0 \\
& \frac{\partial S_{t}^{h}}{\partial p^{e R}}>0
\end{aligned}
$$

$\mathrm{T}$

So Lyapunov function in equation (22) under the innovated land biding method changed into:

$$
\begin{gathered}
V(D(\bullet)-S(\bullet))=\frac{1}{2} k\left(\left(D^{r}(\bullet)+D^{i}(\bullet)+\right.\right. \\
\left.\left.D^{s}(\bullet)\right)-S^{h}\left(p^{e h}, p^{e R}\right)\right)^{2}
\end{gathered}
$$

Derivative (35) with respect to time, we get: 


$$
\begin{aligned}
& \dot{V}=k \cdot\left(D^{h}(\bullet)-S^{h}(\bullet)\right)\left(\frac{\partial D^{r}(\bullet)}{\partial p^{h}}+\frac{\partial D^{r}(\bullet)}{\partial p^{e R}} \cdot \frac{\partial p^{e R}}{\partial p^{l}} \cdot \frac{d p^{l}}{d p^{h}}\right. \\
& +\frac{\partial D^{i}}{\partial p^{h}} \cdot+\frac{\partial D^{i}}{\partial p^{e R}} \cdot \frac{\partial p^{e R}}{\partial p^{l}} \cdot \frac{d p^{l}}{d p^{h}}+\frac{\partial D^{s}}{\partial\left(D^{r}+D^{i}\right)} \cdot \\
& \left(\frac{\partial\left(D^{r}+D^{i}\right)}{\partial p^{h}}+\frac{\partial\left(D^{r}+D^{i}\right)}{\partial p^{e R}} \cdot \frac{\partial p^{e R}}{\partial p^{l}} \cdot \frac{d p^{l}}{d p^{h}}\right)+\frac{\partial D^{s}}{\partial p^{e p}} \cdot \frac{\partial p^{e p}}{\partial p^{l}} \cdot \frac{d p^{l}}{d p^{h}} \\
& -\left(\frac{\partial S^{h}}{\partial p^{e h}} \cdot \frac{\partial p^{e h}}{\partial p^{l}} \cdot \frac{d p^{l}}{d p^{h}}+\frac{\partial S^{h}}{\partial p^{e R}} \cdot \frac{\partial p^{e R}}{\partial p^{l}} \cdot \frac{d p^{l}}{d p^{h}}\right) \cdot \frac{d p^{h}}{d t}
\end{aligned}
$$

$$
\begin{aligned}
& \dot{V}=k^{2} \cdot\left(D^{h}(\bullet)-S^{h}(\bullet)\right)^{2}\left(\frac{\partial D^{r}(\bullet)}{\partial p^{h}}+\frac{\partial D^{r}(\bullet)}{\partial p^{e R}}\right. \\
& \cdot \frac{\partial p^{e R}}{\partial p^{l}} \cdot \frac{d p^{l}}{d p^{h}}+\frac{\partial D^{i}}{\partial p^{h}}+\frac{\partial D^{i}}{\partial p^{e R}} \cdot \frac{\partial p^{e R}}{\partial p^{l}} \cdot \frac{d p^{l}}{d p^{h}} \\
& +\frac{\partial D^{s}}{\partial\left(D^{r}+D^{i}\right)} \cdot\left(\frac{\partial\left(D^{r}+D^{i}\right)}{\partial p^{h}}+\frac{\partial\left(D^{r}+D^{i}\right)}{\partial p^{e R}}\right. \\
& \left.\frac{\partial p^{e R}}{\partial p_{t}^{l}} \cdot \frac{d p^{l}}{d p^{h}}\right)+\frac{\partial D^{s}}{\partial p^{e p}} \cdot \frac{\partial p^{e p}}{\partial p^{l}} \cdot \frac{d p^{l}}{d p^{h}}- \\
& \left.\left(\frac{\partial S^{h}}{\partial p^{e h}} \cdot \frac{\partial p^{e h}}{\partial p^{l}} \cdot \frac{d p^{l}}{d p^{h}}+\frac{\partial S^{h}}{\partial p^{e R}} \cdot \frac{\partial p^{e R}}{\partial p^{l}} \cdot \frac{d p^{l}}{d p^{h}}\right)\right)
\end{aligned}
$$

So we get:

$$
\begin{gathered}
\frac{\partial D^{r}(\bullet)}{\partial p^{h}}+\frac{\partial D^{r}(\bullet)}{\partial p^{e R}} \cdot \frac{\partial p^{e R}}{\partial p^{l}} \cdot \frac{d p^{l}}{d p^{h}}<0 \\
\frac{\partial D^{i}}{\partial p^{h}}+\frac{\partial D^{i}}{\partial p^{e R}} \cdot \frac{\partial p^{e R}}{\partial p^{l}} \cdot \frac{d p^{l}}{d p^{h}}<0 \\
\frac{\partial D^{s}}{\partial\left(D^{r}+D^{i}\right)} \cdot\left(\frac{\partial\left(D^{r}+D^{i}\right)}{\partial p^{h}}+\right. \\
\left.\frac{\partial\left(D^{r}+D^{i}\right)}{\partial p^{e R}} \cdot \frac{\partial p^{e R}}{\partial p^{l}} \cdot \frac{d p^{l}}{d p^{h}}\right)+\frac{\partial D^{s}}{\partial p^{e p}} \cdot \frac{\partial p^{e p}}{\partial p^{l}} \cdot \frac{d p^{l}}{d p^{h}}
\end{gathered}
$$

The signal of above is uncertain;

$$
\frac{\partial S^{h}}{\partial p^{e h}} \cdot \frac{\partial p^{e h}}{\partial p^{l}} \cdot \frac{d p^{l}}{d p^{h}}+\frac{\partial S^{h}}{\partial p^{e R}} \cdot \frac{\partial p^{e R}}{\partial p^{l}} \cdot \frac{d p^{l}}{d p^{h}}
$$

The signal of above is uncertain..

\section{The rational speculator bring the price mechanism robustness regulator}

Under the innovated land biding method, the signal of Lyapunov function of Chinese real estate market derivative with respect to time is uncertain.

Under the innovation method, the increase of house price leads the increase of "land price", it brings the expectation of increase cost of house for sell and decrease of rental, the trade-off between buying and renting, the increase of cost of house for sell do not means the increase price of house for sell, because the increase of cost of house for sell must be accompanied with the decrease of resident demand and investment demand. For the rational speculator, the increase of "land price" means the increase of expected price of house and the decrease of chance to sell, so the increase of "land price" cannot leads to the increase of speculation demand.

The same problem for house supply, the increase of "land price" means the increase of expected price of house accompanied with the decrease of chance for house to sell, it is irrational to decrease supply.

So:

$$
\begin{aligned}
& \frac{\partial D^{s}}{\partial\left(D^{r}+D^{i}\right)} \cdot\left(\frac{\partial\left(D^{r}+D^{i}\right)}{\partial p^{e h}} \cdot \frac{\partial p^{e h}}{\partial p^{l}} \cdot \frac{d p^{l}}{d p^{h}}\right. \\
& \left.+\frac{\partial\left(D^{r}+D^{i}\right)}{\partial p^{e R}} \cdot \frac{\partial p^{e R}}{\partial p^{l}} \cdot \frac{d p^{l}}{d p^{h}}\right)+\frac{\partial D^{s}}{\partial p^{e p}} \cdot \frac{\partial p^{e p}}{\partial p_{t}^{l}} \cdot \frac{d p^{l}}{d p^{h}}<0 \\
& \frac{\partial S^{h}}{\partial p^{e h}} \cdot \frac{\partial p^{e h}}{\partial p^{l}} \cdot \frac{d p^{l}}{d p^{h}}+\frac{\partial S^{h}}{\partial p^{e R}} \cdot \frac{\partial p^{e R}}{\partial p^{l}} \cdot \frac{d p^{l}}{d p^{h}}>0
\end{aligned}
$$

So, the Lyapunov function of Chinese house market under the innovated land biding method has:

$$
\dot{V}(\bullet)<0
$$

the innovated method of land biding return the robustness to Chinese real estate market, the market with robustness regulator is price steady and becomes efficient in resource allocate again.

\section{CONCLUSION}

We get the conclusion of this paper:

Chinese real estate market is abnormal, the price mechanism of this market has no robustness when the speculation is current;

It is an efficient way to return the robustness to Chinese real estate market by the innovated land biding method, that is change the one who pay the most money to government gets the land to develop into the one who return the highest proportion of house to government gets the land to develop, and the government lease the houses drafted in random at the price of market clear.

There is no doubt about the validity of price mechanism, but under the special condition of China, some adjustments must be made. The innovation that makes the price mechanism valid in China has theoretical contribution.

\section{REFERENCES}

[1] Gregory, Chow, and Lilin Niu, 2010, Demand and Supply for Residential Housing in Urban China. Journal of Financial research, $1,1-11$

[2] Houjun, 2010, The Solution of House Dilemma. China Economic Weekly, 10.

[3] Kindleberger, Charles, 1978, Manias, panics, and crashes: A History of Financial Crises. MIT press.

[4] Kuang Weida. Expectation, Speculation and Urban Housing Price Volatility in China . Economic Research Journal, 2010, 9 : 6778 . 
[5] Li Zun-bai, 2010, Analysis of the Stake Dilemma in Supportive Policy for High-price of Houses, China soft science, 4, 37-43.

[6] Zhang Jinshui, 1999, Economic Cybernetics. Beijing: Tsinghua university press

[7] Zhang Jinyan, 2000, Differential Equations: Geometric Theory and Bifurcation. Beijing: Peking university press.
[8] Sandal L.K., Dynamic Cournot-competitive harvesting of a common pool resource[J]. Journal of Economic Dynamics and Control,2004,28(9):1781-1799.

[9] Szidarovszky F. Dynamic Cournot oligopoliies with production adjustment cost[J]. Journal of Mathematical Economics,1995,24(1):95-101

[10] Qiu L.D.,On the dynamic efficiency of Bertrand and Cournot equilibria[J]. Journal of Economic Theory, 1997,75(1):213-22 